\title{
Universiteit
}

Leiden

The Netherlands

\section{Environmental impacts of the nutrition transition and potential hunger eradication in emerging countries}

Bamberger, M.; Behrens, P.A.; Scherer, L.

\section{Citation}

Bamberger, M., Behrens, P. A., \& Scherer, L. (2021). Environmental impacts of the nutrition transition and potential hunger eradication in emerging countries. Sustainability Science, 16, 565-579. doi:10.1007/s11625-020-00887-7

Version:

Publisher's Version

License:

Licensed under Article 25fa Copyright Act/Law (Amendment Taverne)

Downloaded from: https://hdl.handle.net/1887/3249406

Note: To cite this publication please use the final published version (if applicable). 


\title{
Environmental impacts of the nutrition transition and potential hunger eradication in emerging countries
}

\author{
Max Bamberger ${ }^{1} \cdot$ Paul Behrens $^{1,2} \cdot$ Laura Scherer $^{1}$ (D)
}

Received: 10 November 2019 / Accepted: 24 November 2020 / Published online: 4 January 2021

๑) Springer Japan KK, part of Springer Nature 2021

\begin{abstract}
The shift from traditional diets to a diet characterised by higher consumption of sugars, fats, processed foods and animalsource foods is often termed the nutrition transition. Although research has focused on the health outcomes of this transition, there is an increasing interest in environmental impacts. Here we investigated the potential changes in impacts driven by the nutrition transition in Brazil, China, India, Indonesia, Mexico, South Africa and Turkey between 2011 and 2030. We combined a multi-regional input-output database (EXIOBASE) with food demand projections (OECD-FAO Agricultural Outlook 2018). In a business-as-usual scenario, we assessed the impacts of the projected dietary changes on climate change, marine and freshwater eutrophication, land stress and water scarcity. Then, we built a second, zero-hunger scenario to investigate the impacts due to the eradication of hunger by 2030, a target of Sustainable Development Goal 2. The results show that total growth in environmental impacts through food consumption is the highest for Indonesia (44-54\%), India (35-43\%) and Mexico (31-48\%). The total impacts stay highest in Brazil (land stress), China (eutrophication) and India (climate change and water scarcity), mainly driven by meat, fish and dairy consumption, respectively. The zero-hunger scenario results in similar health improvements across all countries: 0.08 to 0.12 prevented disability-adjusted life years (DALYs) per undernourished person. It would achieve the highest health improvements in India and China with around 375,000 human life equivalents of prevented DALYs combined. There are only slight trade-offs between hunger eradication and environmental goals.
\end{abstract}

Keywords Consumption-based accounting $\cdot$ Multi-regional input-output analysis $\cdot$ Food demand $\cdot$ Dietary change $\cdot$ Zero hunger - Environmental sustainability

\section{Introduction}

Popkin (1993) divided the overall dietary development of the human species into five distinct patterns: (1) collecting food, (2) famine - a monoculture diet dominated by cereals, (3) receding famine — a starchy non-diverse diet high in fibre

Handled by Laura Pereira, Stellenbosch University Centre for complex systems in transition, South Africa.

Supplementary Information The online version contains supplementary material available at https://doi.org/10.1007/s1162 5-020-00887-7 .

Laura Scherer

1.a.scherer@cml.leidenuniv.nl

1 Institute of Environmental Sciences (CML), Leiden University, Leiden, The Netherlands

2 Leiden University College The Hague, The Hague, The Netherlands and low in fat, (4) chronic diseases - a more diversified diet with increased uptake of sugar, (animal) fat and processed foods and (5) behavioural change-increased intake of fruit, vegetables and whole grains. The move from the third to fourth pattern is termed the nutrition transition, a transition already underway across many emerging nations. Global meat consumption tripled between 1960 and 2000 (Roser and Ritchie 2017). Most of this growth can be attributed to the nutrition transition in emerging countries, with the uptake of pork in China as a primary example (Godfray et al. 2018). This transition is also proceeding much faster than the previous transition seen in high-income nations (Guyomard et al. 2013). Although transitions generally show specific national characteristics, all past transitions have entailed an increase in the consumption of animal-source foods (ASF) (Popkin 1993; Smil 2002). Rising affluence, urbanisation and various cultural norms have driven this increased demand for ASF in emerging countries (Milford et al. 2019). 
Another important trend is continuing food insecurity around the world. There are still many millions of people living with food insecurity. Although the first target of the UN Sustainable Development Goal 2 (SDG2) is a world without hunger (UN 2018), about 800 million people are still chronically undernourished (Ramankutty et al. 2018). Between 2015 and 2018, global hunger has risen to the same level as a decade ago (Cohen 2019). At the same time, the over-consumption of ASF in the fourth pattern of the dietary development has resulted in an uptick in obesity and noncommunicable diseases (Smith et al. 2013). Consequently, the largest body of research on the nutrition transition focuses on health implications and especially the double burden of undernutrition and obesity.

Food systems also have severe environmental impacts (Godfray et al. 2010). Among all food products, the environmental impacts of ASF are disproportionately high across many impact categories (Aiking 2011), with a few exceptions, such as water consumption when considering consumption volumes (Harris et al. 2020). Livestock-based food production represents one of the major human-made drivers of environmental degradation. It is the cause of about onefifth of global greenhouse gas (GHG) emissions, and a key land user, water polluter as well as a promotor of species extinctions (Machovina et al. 2015).

Although several authors have warned of a potential increase in environmental impacts due to the nutrition transition, a thorough, quantitative analysis is lacking (to the authors' knowledge). Gill et al. (2015) restricted their analysis on environmental impacts of dietary changes in Brazil, China and India to selected food products. The study of Aleksandrowicz et al. (2019) focuses only on India. Furthermore, the pursuit of various SDGs may conflict with each other and lead to trade-offs. Scherer et al. (2018) evaluated interactions between social and environmental SDGs, concluding that the achievement of social goals may entail higher environmental impacts. The issues of sufficient food supply and environmental sustainability form a nexus, as dietary shifts often imply adverse environmental impacts. Understanding these interactions is important to minimise the impacts of future dietary change.

Here we aim to (1) estimate the potential environmental impacts of predicted dietary change in emerging countries in 2030 and (2) estimate the health benefits of eradicating hunger and their potential trade-offs with environmental goals. Since countries follow different diets and nutrition transitions, comparative, country-specific analysis is important. We investigate several emerging countries that are estimated to have much greater levels of ASF consumption in the future if current socio-economic trends continue. These countries are China, India, Brazil, Mexico, Indonesia, Turkey and South Africa. Including Russia would complete the BRICS countries, but Russia shows different characteristics than the chosen countries, such as a decreasing population and stagnating urbanisation. As such, we expect Russia's nutrition transition and consequent environmental impacts to be less significant. To address the two research objectives, we assess a business-as-usual scenario where the impacts of the nutrition transition are investigated until 2030. A second scenario investigates the fulfilment of SDG2 (zero hunger) in 2030, using the diets obtained from the business-as-usual scenario as a starting point. We then evaluate any potential trade-offs between social and environmental goals.

\section{Materials and methods}

\section{Scenario analysis for $\mathbf{2 0 3 0}$}

\section{Business-as-usual scenario on the nutrition transition}

For dietary data in the business-as-usual scenario, we used the Agricultural Outlook (AO) (OECD and FAO 2018), a global, country-specific agricultural market projection for 27 food commodities over a 10-year timeframe. All food commodities included in the AO are shown in Table A2 (Supplementary Information). The Food and Agriculture Organisation of the UN (FAO) publishes the AO in collaboration with the Organisation of the Economic Co-operation and Development (OECD). The main advantage of the AO over other projections is that it is updated annually (OECD 2018) and so continuously estimates future nutrition transitions.

OECD and FAO (2018) follow three main steps to obtain a global baseline projection of the agricultural market:

1. The data are collected through national statistical offices via a questionnaire on expected agricultural developments.

2. Aglink-Cosimo, a partial equilibrium model of world agricultural markets (OECD and FAO 2015), is used to estimate food demand. The model is first run globally to ensure consistent data integration and agreement between global consumption and production of all commodities.

3. The results of the first baseline are reviewed with the help of the questionnaire results and national and international agricultural expert panels. Refinements are made according to the results of these consultations to obtain a final global baseline projection.

The Aglink-Cosimo framework provides supply and demand data on the main agricultural commodities (prices are determined by regional or international equilibria of supply and demand and non-agricultural markets are exogenous to the model). The model is recursive-dynamic, i.e. outcomes for one year influence the respective outcomes in the 
following year. Commodity quality is assumed to be homogeneous and buyers do not distinguish between countries of origin. Underlying model determinants include current agricultural market conditions as well as macroeconomic, political and demographic assumptions, such as population, real gross domestic product (GDP), deflators of GDP and of private consumption expenditure and monetary exchange rates.

Since the AO has been published for the last ten years, starting in 2009, we present a brief analysis of its accuracy over time by comparing previously projected to actual food use (see results in Sect. 3.2). For all commodities, we evaluated observed data and the most recent projection against linear, exponential and logarithmic trends. A linear model showed the best fit for all commodities. Since the AO data finish in 2027 , we then linearly extrapolated the data by commodity until 2030. Only consumption data labelled as "food" were used (rather than production for other uses such as feed and fuel). Note that feed is considered indirectly as an upstream process to produce ASF.

For the business-as-usual scenario, we investigated the plausibility of the results for per-capita (p.c.) consumption by comparing against the current, global maximum of p.c. national supply. We see this supply level as a logical saturation point and hence checked for any results exceeding these levels by commodity in between today and 2030. There was no significant food consumption of fish meal, fish oil, distiller's dry grains, molasses, protein meals, raw sugar, white sugar and whey powder. These commodities can be classified as intermediate products which are not demanded by households for direct food consumption.

\section{Zero-hunger scenario}

The zero-hunger scenario modifies the business-as-usual scenario to quantify the environmental impacts related to the potential eradication of hunger by 2030 , as proposed by SDG2. Here, the diets followed by all countries are of the same composition as AO projections for 2030, as used in the business-as-usual scenario, but we increased the total dietary energy available to reflect the zero-hunger target.

To make this estimation, we have to determine the potential level of undernourishment by 2030 . We began with the FAO's regular update on the prevalence of undernourishment, i.e. the undernourished proportion of the national population. As this proportion does not provide insight into the food supply gap of the undernourished population, the FAO publishes the depth of the food deficit (Roser and Ritchie 2018a). The depth of the food deficit compares the average dietary energy consumption of the undernourished population with the average dietary energy requirement (ADER) of the country's population and provides a weighted average deficit in kcal p.c. per day of the whole population. The
ADER is defined as "the caloric intake required to provide energy balance in a given individual of a healthy weight for their gender, age and activity levels" (Roser and Ritchie 2018b).

Calculation of the depth of the food deficit requires knowledge of the prevalence of undernourishment, which in turn is based on the minimum dietary energy requirement (MDER). The MDER is measured in kcal p.c. per day and commonly accepted as a level of threshold caloric intake to define the prevalence of undernourishment (Roser and Ritchie 2018b). Once the caloric intake of an individual falls below the MDER for an extended period, the individual is regarded as undernourished. The food security indicators of FAOSTAT (FAO 2018) provide data on the average ADER and MDER levels of a country's population, based on the demographic weighting (Roser and Ritchie 2018b).

We used the total food deficit (TFD) of a country as well as the prevalence of undernourishment (PoU) to determine the depth of the food deficit (DFD), as illustrated by Moltedo et al. (2014):

$\mathrm{DFD}=\mathrm{TFD} \cdot \mathrm{Po} U=\left(\mathrm{ADER}-c_{\text {under }}\right) \cdot P o U$,

where $c_{\text {under }}$ is the average consumption of the undernourished population.

$c_{\text {under }}$ results from the average consumption of the individuals within a country whose consumption falls below the MDER in the dietary energy consumption distribution:

$c_{\text {under }}=\frac{\int_{0}^{\mathrm{MDER}} x f(x) \mathrm{d} x}{\int_{0}^{\mathrm{MDER}} f(x) \mathrm{d} x}$.

We modelled dietary energy consumption at the national level using a lognormal distribution (Naiken 2003, 2014). $f(x)$ is the probability density function of a lognormal distribution:

$f(x)=\frac{1}{x \sigma \sqrt{2 \pi}} \exp \left(-\frac{(\ln (x)-\mu)^{2}}{2 \sigma^{2}}\right), x>0$.

The indefinite integral of the density function is:

$\int f(x) \mathrm{d} x=F(x)=\frac{1}{2} \operatorname{erf}\left(\frac{\ln (x)-\mu}{\sqrt{2} \sigma}\right)+C$,

where erf is the error or Gauss error function.

The calculation of the prevalence of undernourishment is based on the two parameters that form the lognormal distribution: the national p.c. dietary energy consumption and its coefficient of variation. The data on the dietary energy supply was used as a proxy for energy consumption (INDDEX Project 2018). This ensures consistency among all countries, as most countries do not have nationally representative 
dietary intake surveys. To better match supply values with actual consumption, data on region-specific average waste percentages at the household level (Gustavsson et al. 2011) was taken into account.

In addition, caloric supply may vary significantly within a country. The inequality of caloric intake within a nation is measured using the coefficient of variation of the habitual caloric consumption distribution $(\mathrm{CV}(x))$ (Roser and Ritchie 2018b). The prevalence of undernourishment (PoU) is calculated with:

$P o U \equiv \int_{0}^{x<M D E R} f(x) \mathrm{d} x$.

We determined the two parameters $\mu$ and $\sigma$ of the density function of the lognormal distribution (Eq. 3) as follows:

$\mu=\ln (\bar{x})-\frac{\sigma^{2}}{2}$,

$\sigma=\sqrt{\ln \left(C V^{2}(x)+1\right)}$,

where $\mu$ is the location parameter or geometric mean, $\sigma$ the scale parameter or geometric standard deviation and $x$ the average dietary energy supply p.c. in kcal/day, corrected for food waste.

The caloric intake of many people in most countries fell close to the minimum dietary energy requirement, so precise quantification was critical for the subsequent calculation of the prevalence of undernourishment. The minimum dietary energy requirements differ across the world, as they depend on the country-attained height and population structure for different age groups by gender. We followed the FAO (2008) to compute the minimum dietary energy requirement (MDER):

$\operatorname{MDER}=\sum_{i j}\left(\operatorname{LLER}_{i j} \bullet p_{i j}\right)+\mathrm{PA}$,

where LLER is the lower limit of energy requirement p.c. per day of a given age and sex group, $p_{i j}$ the proportion of each age and sex group of the total population and PA the pregnancy allowance. The World Population Prospects (UN 2017) includes projections of the share of gender and 5-year age groups of the total population which were used to project the minimum dietary energy requirement. Our calculation of the lower limit of energy requirement is presented in the Supplementary Text. The Supplementary Information also shows projections for attained height (Fig. A1), dietary energy supply (Fig. A2), average daily energy requirement (Fig. A3) and the coefficient of variation for the habitual caloric consumption distribution (Fig. A4).

The food balance sheets of FAOSTAT provide data to calculate the proportion of a subcategory to the total dietary energy supply for each food category in 2011. The respective ratio was considered constant over time per food category and country and was therefore applied to the changed diet in 2030, which was extracted from the AO. This required harmonisation between FAOSTAT and the AO. After harmonisation (Table A3 in the Supplementary Information), the nutritional value (in $\mathrm{kcal} / \mathrm{kg}$ ) for the AO food categories were calculated for each of the countries. There are many more FAOSTAT products, so the nutritional value of each AO product was based on the contribution of the FAOSTAT subproducts to the main product in 2011. Thus, it was assumed that these shares are constant due to a lack of disaggregated data. For cheese, high fructose corn syrup and milk powder, no nutritional information was available. These values were taken from the USDA Food Composition Database (USDA 2019).

To allow for accurate projections, the prevalence of undernourishment and depth of food deficit were first reproduced for 2013. Here, some of the calculated prevalence of undernourishment values deviated considerably from the FAO values. These deviations were used as bias correction factors when calculating the projected prevalence of undernourishment for 2030. The projections of the depth of food deficit were used to increase food consumption levels in 2030 to reflect the remaining existence of hunger before eradication.

\section{Health impacts}

Disability-adjusted life years (DALYs) are a commonly used metric of the global burden of disease (Kassebaum et al. 2016). DALYs sum years of life lost due to premature mortality and years lived with disability due to diseases or injuries. Lowering the depth of food deficit brings about a health benefit by reducing protein-energy malnutrition. DALYs due to protein-energy malnutrition are an indicator of the burden of undernourishment or chronic hunger which, despite big improvements, exceeds the burden of hidden hunger due to micronutrient malnutrition (Gödecke et al. 2018). The UN Environment Life Cycle Initiative recommends a health effect factor of $4.55 \times 10^{-8} \mathrm{DALY} / \mathrm{kcal}$ (Jolliet et al. 2018). Life expectancies at birth (The World Bank 2019) were projected until 2030 so health improvements could be given in terms of human life equivalents of prevented DALYs.

\section{Environmental impacts}

Globalisation has driven an increasing complexity in the production and consumption of goods through trade. We used an environmentally extended input-output analysis (EEIOA) to trace emissions, resource use and environmental impacts through international supply chains (Gallego and 
Lenzen 2006; Lenzen et al. 2007; Mäenpää and Siikavirta 2007; Munksgaard and Pedersen 2001).

EEIOA tables are generally in monetary units (e.g. EUR), as physical data are rarely available. By combining the input-output data $(L)$ with an environmental coefficient matrix $(C)$, the total change of emissions or resource use $(\Delta b)$ resulting from a change in final demand $(\Delta y)$ can be calculated:

$\Delta b=C \cdot L \cdot \Delta y+\Delta e_{\text {dir }}$,

where $\Delta e_{\text {dir }}$ is the change of direct environmental impacts.

We used EXIOBASE 3, a time series of multi-regional input-output tables for 44 countries and five remaining world regions from 1995 to 2011 (Stadler et al. 2018). EXIOBASE has been used to evaluate the environmental impacts of national dietary recommendations (Behrens et al. 2017; Scherer et al. 2019) and benefits of food waste reductions in the EU (Usubiaga et al. 2017). AO food categories were harmonised with EXIOBASE food categories (Table A2, Supplementary Information). Subsequently, AO demand projections were used to change the monetary household demand vector for the countries investigated. Not all parts of the nutrition transition could be studied, as EXIOBASE holds no food categories to evaluate a change in demand for processed food products.

This study accounts for five impact categories: (1) climate change, (2) marine eutrophication, (3) freshwater eutrophication, (4) land stress and (5) water scarcity. We applied characterisation models to the results of the EEIOA calculations to conduct an impact assessment. Here, only midpoint models which provide indicators that describe environmental problems were used. In the order of the impact categories above:

- The carbon footprint is expressed as the impact on climate change in carbon dioxide $\left(\mathrm{CO}_{2}\right)$ equivalents using the global warming potential at a 100 -year time horizon (Myhre et al. 2013).

- The eutrophication potential indicates the contribution of a substance to eutrophication, divided into freshwater and marine eutrophication, using phosphorus $(\mathrm{P})$ and nitrogen $(\mathrm{N})$ equivalents. This considers the molecular mass of different $\mathrm{P}$ and $\mathrm{N}$ compounds and a fate factor describing the level of the emissions reaching the aquatic environment. This fate factor was assumed to be 1 for emissions to water, 0.3 for $\mathrm{N}$ emissions to air and 0.1 for P emissions to soil (Bouwman et al. 2009).

- Agricultural commodities are water-intensive. Instead of accounting for total water consumption, a regionalised evaluation of water-related impacts is required due to the high variation of impacts depending on geographical factors, such as freshwater availability and freshwater use patterns. For this purpose, we used the water scarcity footprint in $\mathrm{m}^{3}$ equivalents. In contrast to the water footprint as defined by the water footprint network, which is volumetric, the water scarcity footprint is impact-oriented (Pfister et al. 2017). It is based on water scarcity indices ranging from 0.01 to 1 (Pfister and Bayer 2014; Scherer and Pfister 2016). Water scarcity indices relate to a consumption-to-availability ratio.

- Similarly, a regionalised evaluation of anthropogenic land occupation is critical, as biodiversity is characterised by high spatial heterogeneity. For this, the land stress footprint in $\mathrm{m}^{2}$ equivalents, introduced by Pfister et al. (2011), was calculated using land stress indices.

\section{Results}

\section{Environmental impacts of diets in 2011}

Total environmental impacts through food consumption in the base year 2011 were highest for China, Brazil and India (Fig. 1). India and China had the highest total carbon footprint $\left(0.7 \mathrm{Gt} \mathrm{CO}_{2}\right.$ eq.). China saw the highest freshwater eutrophication (7.3 Mt P eq.) and marine eutrophication (0.9 Mt $\mathrm{N}$ eq.). Brazil showed the highest land stress footprint (1.1 million $\mathrm{km}^{2}$ eq.), while the water scarcity footprint was the highest in India (460 billion $\mathrm{m}^{3}$ eq.).

The contribution of meat to the environmental impacts of diets was highest for Brazil (17-56\%) and Mexico (10-41\%) and intermediate for China and Indonesia. China was the only country in which fish consumption contributed appreciably to overall impacts (10-30\%). Dairy consumption contributed most to the impacts of Brazil (4-27\%) and India (3-22\%), as well as the land stress footprints of South Africa, Mexico and China (23-43\%). Sugar consumption played a negligible role, except for the water scarcity footprint of India (5\%). Likewise, vegetable oils and fats only contributed significantly to Indian impact results (2-7\%). In addition, the impact composition varied across the different impact categories. Meat and dairy consumption saw large impacts across climate change $(2-53 \%$ and $2-22 \%$, respectively), land stress (1-46\% and 2-43\%) and marine eutrophication (4-56\% and 5-22\%). Fish consumption contributed more to climate change (1-30\%) than to the other impact categories. Combined ASF consumption contributed least to water scarcity and freshwater eutrophication as compared to other impact categories.

India's high water scarcity footprint and Brazil's high land stress footprint can be explained by their high water scarcity and land stress index, respectively (Pfister et al. 2011). As such, both are influenced more by the food origin than the diet pattern. The characterisation factors for the carbon footprint as well as freshwater and marine eutrophication are not 

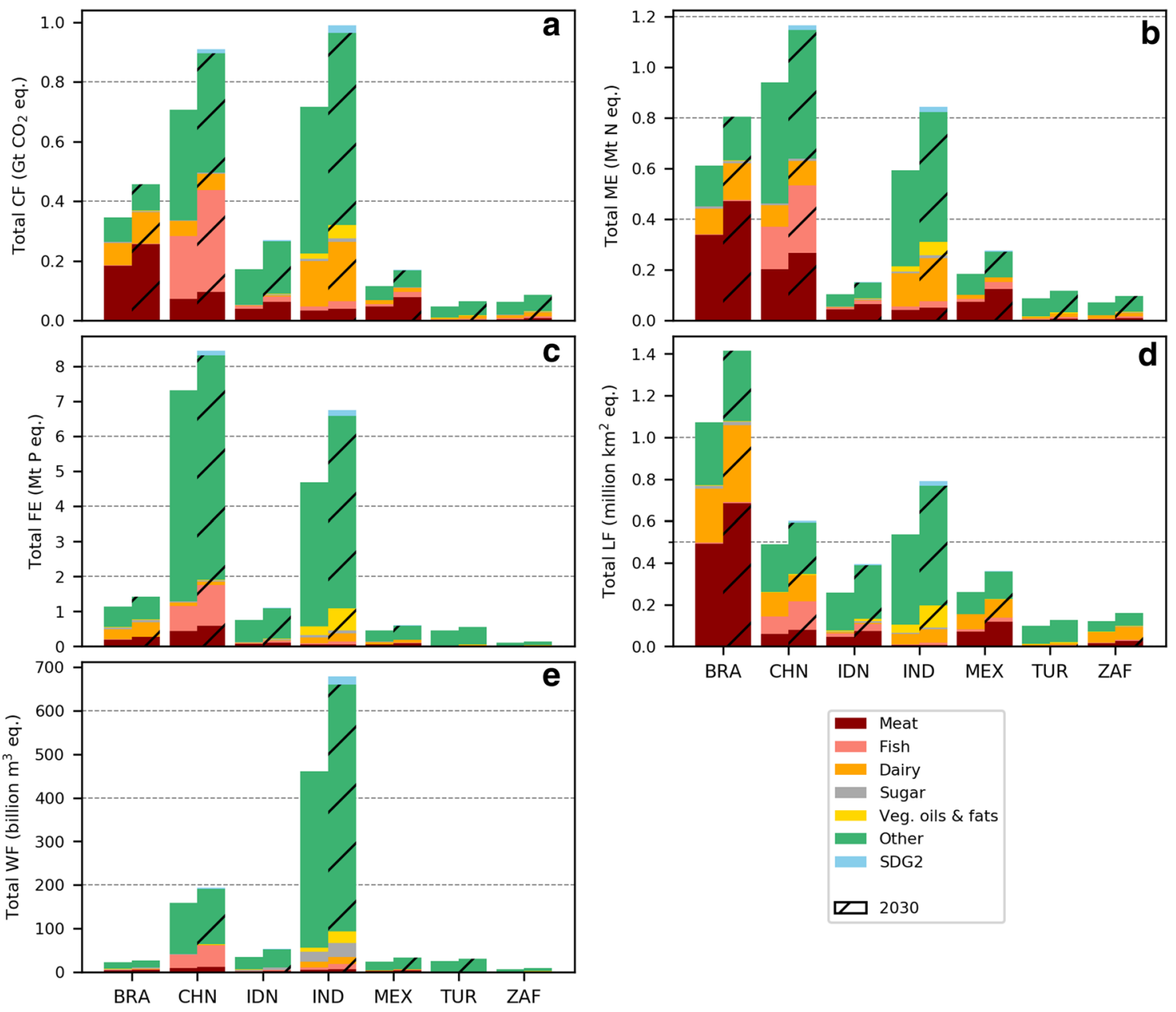

Fig. 1 Total impacts for a carbon footprint (CF), b marine eutrophication (ME), $\mathbf{c}$ freshwater eutrophication (FE), $\mathbf{d}$ land stress footprint (LF) and e water scarcity footprint (WF) in 2011 and in 2030 for scenario A (AO) and scenario B (SDG2)

spatially explicit and, therefore, their results are driven by the diet pattern.

In 2011, Brazil dominated p.c. impacts (Fig. 2), consistent with having the highest GDP p.c. in that year (The World Bank 2019). In 2011, Brazil showed the highest impact results for the carbon footprint (1.7 t $\mathrm{CO}_{2}$ eq.), marine eutrophication ( $3.1 \mathrm{~kg} \mathrm{~N}$ eq.) and land stress $\left(5400 \mathrm{~m}^{2}\right.$ eq. $)$. Turkey caused the highest p.c. freshwater eutrophication (6.1 kg P eq.) and India showed the highest p.c. water scarcity footprint $\left(369 \mathrm{~m}^{3}\right.$ eq. $)$.

\section{Environmental impacts in 2030 in the business-as-usual scenario}

The population is projected to increase in all studied countries (Fig. A5, Supplementary Information). Generally, AO projections provide higher accuracy for the near future and see larger divergences the further into the future they go (Fig. A6 and Supplementary Text). According to the AO of 2018, p.c. meat and fish consumption will grow in all countries until 2030 (Fig. 3). P.c. dairy consumption will grow considerably for India and Turkey, p.c. sugar consumption will grow considerably for China and Indonesia and p.c. consumption of vegetable oils and fats will grow most in India and Indonesia (Table A4, Supplementary Information). Consumption of other food will remain at a similar level, except for Indonesia and Mexico. The increases will be dominated by consumption of wheat in Indonesia and coarse grains and oilseeds in Mexico.

The increased consumption of ASF in 2030 is set to increase consumption-based total environmental impacts (Fig. 1). We estimate that total impact increases would be the highest for Indonesia (44-54\%, especially the carbon footprint), India (35-43\%, especially the land stress footprint) and Mexico (31-48\%, especially marine eutrophication). South Africa would see the largest increase to its water scarcity footprint (38\%) and Turkey and China to its carbon footprint (34\% and 27\%). Brazil would see the largest 

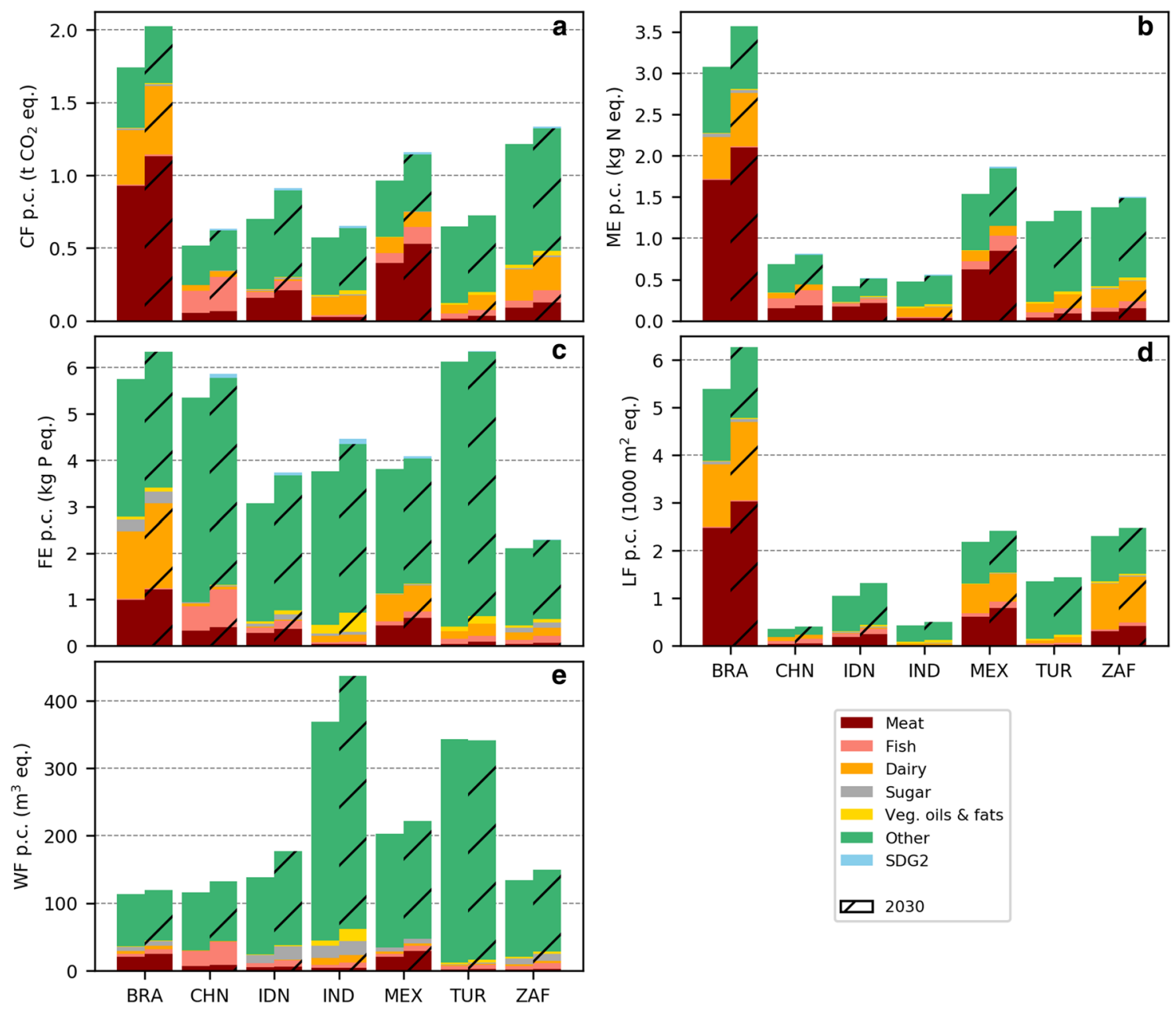

Fig. 2 Per-capita impacts for a carbon footprint (CF), b marine eutrophication (ME), $\mathbf{c}$ freshwater eutrophication (FE), d land stress footprint (LF) and e water scarcity footprint (WF) in 2011 and in 2030 for scenario A (AO) and scenario B (SDG2)

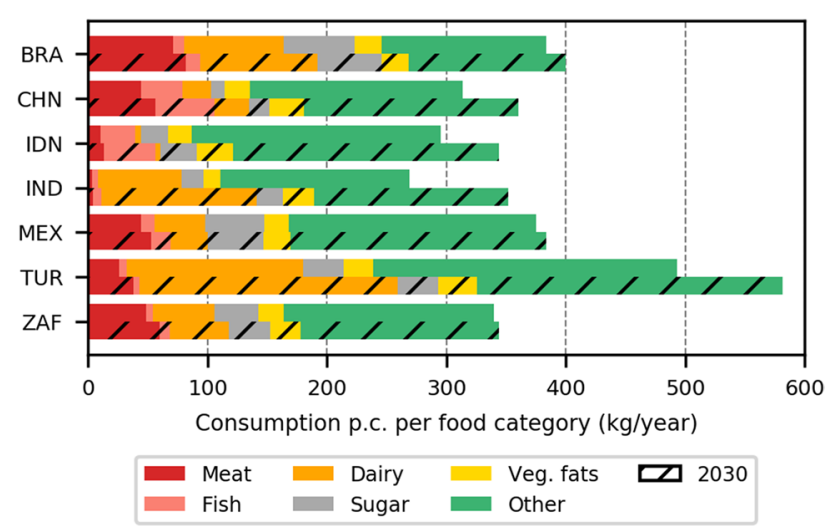

Fig. 3 Per-capita consumption of meat, fish, dairy, sugar, vegetable oils and fats, and other food products in 2011 and 2030 increase almost equally to its land footprint, carbon footprint and marine eutrophication (32\%). Across the seven emerging countries, all impact category results would grow by $25-37 \%$. The growth would be strongest for the water scarcity footprint, followed by the carbon footprint and the land stress footprint (both about 34\%). The high impact increases of India and Indonesia would be mainly driven by population growth, next to high fish consumption increases p.c. in the case of Indonesia and high dairy consumption increases p.c. in the case of India.

Our scenario suggests that, compared to total impact changes, China and South Africa would experience comparatively high p.c. impact growth. The p.c. impact increases for China, Mexico, Turkey and South Africa would be solely based on higher intakes of ASF, sugar and vegetable oils and fats, as impacts of other food categories will remain constant. The high p.c. impacts of Brazil would be due to high levels of red meat consumption, which has the highest marine eutrophication potential and global warming 
potential of all food products and the very high land stress index of Brazil. Brazilian beef demand is primarily sourced locally and produces comparatively high impacts due to methane-emitting cattle (Harper et al. 1999; Xue and Landis 2010; Simoes and Hidalgo 2011).

According to this scenario, the p.c. carbon footprint of the most populous countries China, India and Indonesia would be still much lower than the level of Brazil, which indicates that further growth after 2030 is likely in the future. Across all countries, p.c. impacts would grow by $9-16 \%$, with the strongest growth for the carbon footprint, next to marine eutrophication (15\%) and land stress (14\%).

\section{Environmental and health impacts in $\mathbf{2 0 3 0}$ in the zero-hunger scenario}

Even without modelling the extra food production and consumption needed to meet the zero-hunger target, the depth of food deficit is projected to reduce rapidly across most of the studied countries (Fig. 4b). However, the depths of food deficit in Mexico, Turkey and South Africa are estimated to increase due to a growing prevalence of undernourishment (Fig. 4a) as well as rising minimum and average dietary energy requirements (see Supplementary text). The corresponding food deficit of the undernourished population is estimated to be highest in China, but is of a similar level across all countries (Fig. 4c).

As a result of the developments of the prevalence of undernourishment and the depth of food deficit, the achievement of SDG2 in 2030 would only add a small amount to the total and p.c. environmental impacts of all studied countries (Figs. 1 and 2). For the undernourished population, we assume that increases in impacts follow the impact pattern of the respective country. Upon reaching the average dietary energy requirement as consumption level for all undernourished people, impacts would be close to p.c. impacts of the total population (Fig. 5).

We estimate that zero hunger in 2030 would bring about similar health improvements in all countries of 0.08 to 0.12 prevented DALYs per undernourished person (Fig. 6a). To illustrate the differences between countries, Fig. 6b shows the health improvements in human life equivalents (HLEs) of prevented DALYs of the total undernourished population. Overall, health improvements would be greatest in India (228,000 HLEs) and China (147,000 HLEs).

\section{Discussion}

\section{Environmental impacts of the nutrition transition}

The results of this study illustrate the potential environmental impacts from nutrition transitions across emerging countries. This does not include all the potential changes in the transition, such as rising demand for processed food products. Yet, the results show a clear trend towards higher consumption of ASF, vegetable oils and fats and, for some countries, sugar, all resulting in higher impacts. This analysis also shows how these nations are at different stages of the nutrition transition. In terms of the speed of nutrition transitions across the nations investigated, Indonesia's p.c. impacts are the fastest growing, which implies a rapid nutrition transition until 2030. However, increases in p.c. impacts from "other" food products (like wheat and soya beans) in Indonesia and India indicate that in both countries the adoption of the third pattern of the transition is still increasing in contrast to the other studied countries where the pattern is already more established. It implies that these parts of the populations in Indonesia and India will start transitioning towards the fourth pattern later. The transition progresses at a moderate pace in India and China and at a slower pace in Mexico and Brazil (Figs. 2, 3). This leads to convergence with Western diets by 2030, as Brazil, Mexico and China reach high levels of meat consumption. However, India's transition is very different from other emerging countries. Here, meat consumption grows slowly to 2030 , as especially beef consumption is historically limited due to religious and cultural taboos (Ferry 2020). The possibility of surging poultry and goat meat demand is still debated, as both are viable substitutes for most of the impacted consumers (Begum et al. 2011; Dhanda et al. 2003). An acceleration in economic growth could alter this trend, as Indian consumers slowly move towards consuming more meat, fish and eggs instead of dairy products with rising income (Gandhi and Zhou 2014), while other studies still project an increase in dairy consumption (Alae-Carew et al. 2019). This study's results show that p.c. impacts through Indian meat consumption remain very low. This is important, as India represents $17.6 \%$ of the global population in 2030 (UN 2017). South Africa and Turkey show a slow dietary change, limiting potential increases in environmental impacts.

The business-as-usual scenario can be considered as one of social inertia and represents current trends. Whether this trend will continue into the future is of course uncertain and while a shift from this trend is possible, some research has cast doubt on the societal appetite for dietary change (O'Riordan and Stoll-Kleemann 2015). Likewise, global meat consumption continues to rise although its environmental impacts are known since decades (Subak 1999). However, if the nutrition transition in emerging countries were to progress according to the business-as-usual scenario, associated environmental impacts could directly affect the further course of the nutrition transition in a feedback and thus offset additional environmental impacts (Woodard et al. 2019). This feedback would increase as the agricultural sector 
Fig. 4 Results for a prevalence of undernourishment, $\mathbf{b}$ depth of the food deficit in 2013 and 2030 and $\mathbf{c}$ food deficit per undernourished person in 2030
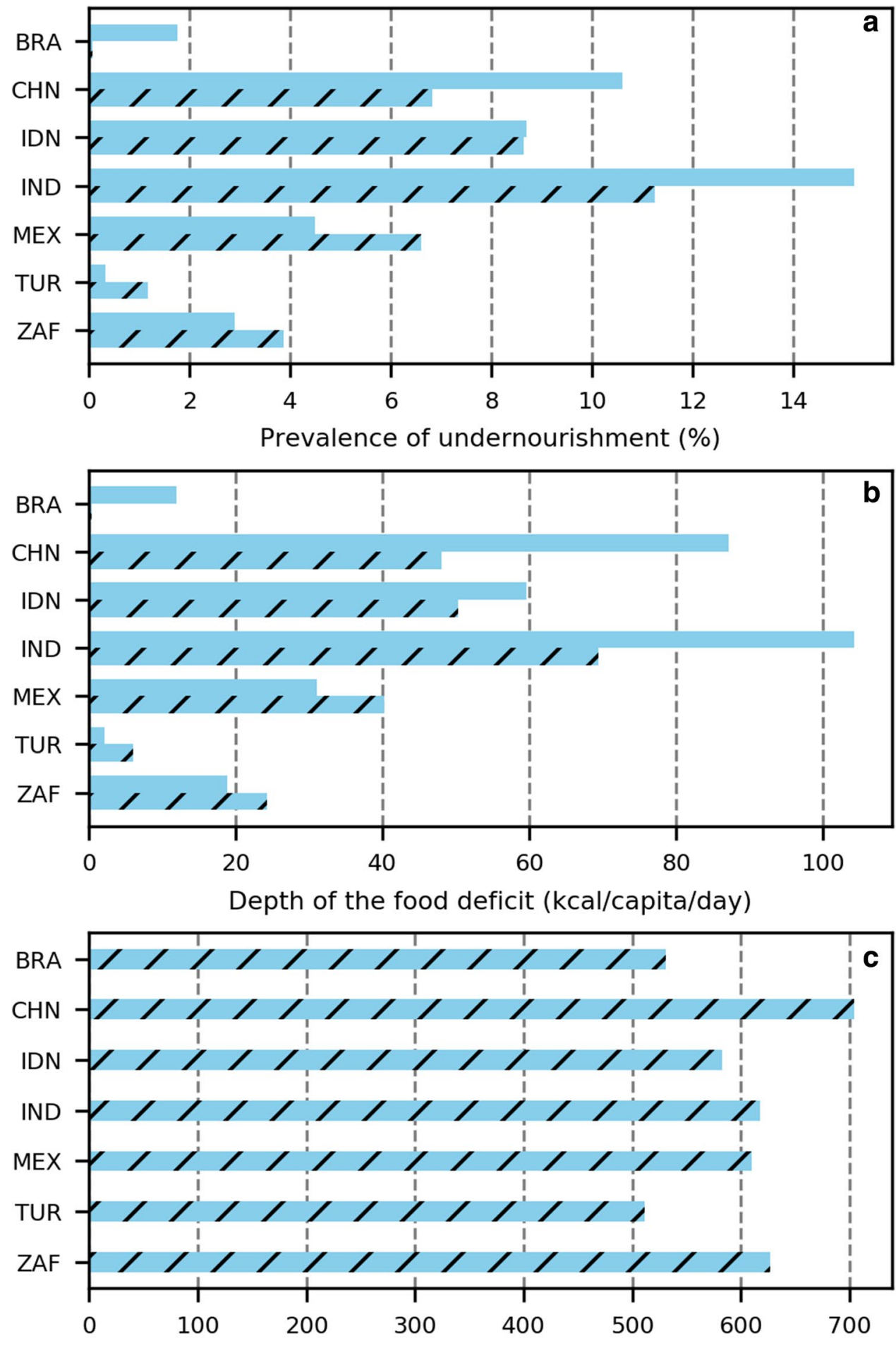

Food deficit per undernourished person (kcal/capita/day)

2030

approaches environmental limits. Limits to growth, such as available arable land, could increase the political will to limit the consumption of ASF or to stimulate more investment in new production techniques. In the course of this, alternatives to conventional meat products, such as plant-based substitutes and in vitro meat, could increasingly compete with livestock (Hocquette 2016). 

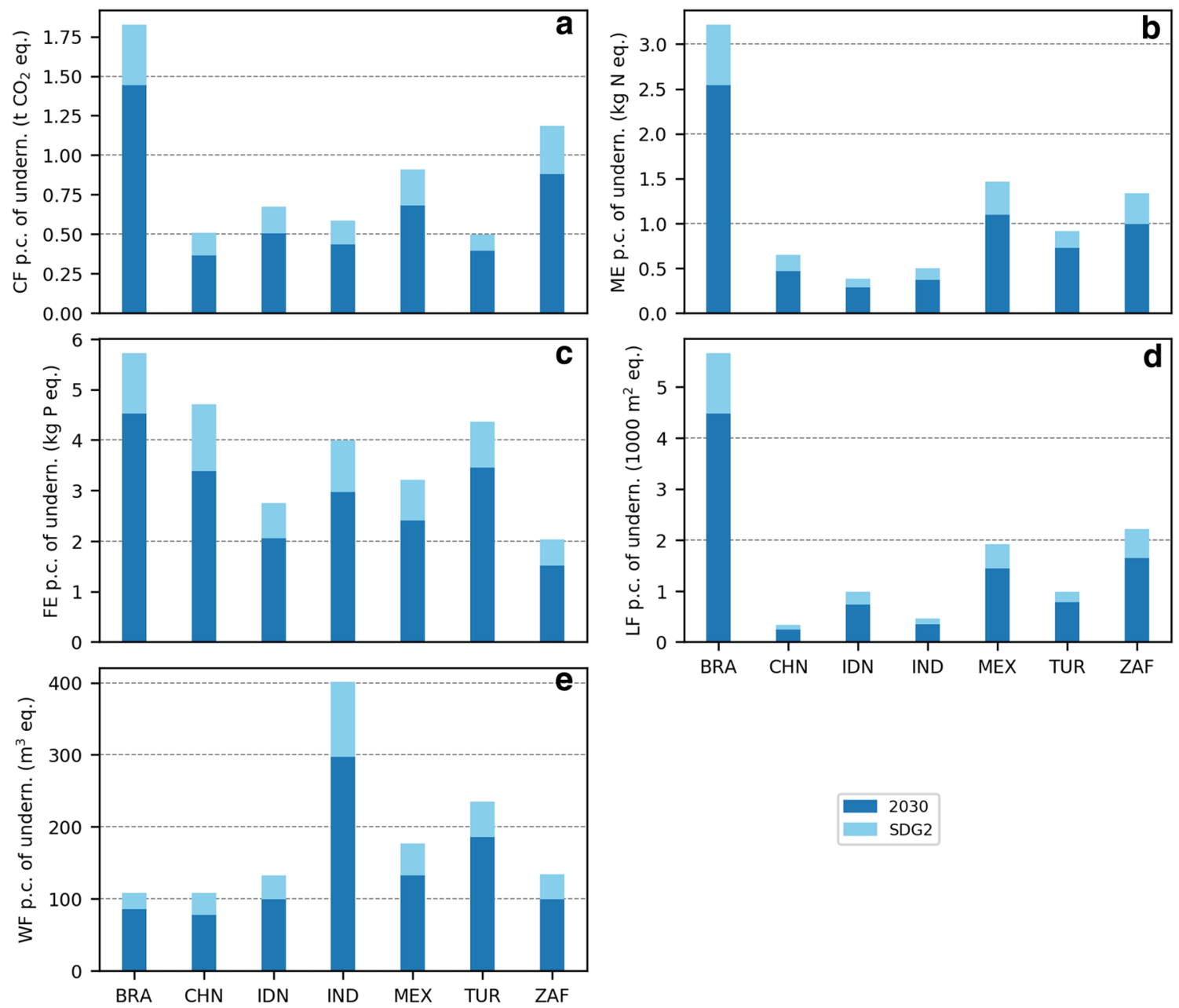

Fig. 5 Per-capita impacts for undernourished part of population for a carbon footprint (CF), b marine eutrophication (ME), $\mathbf{c}$ freshwater eutrophication (FE), $\mathbf{d}$ land stress footprint (LF) and e water scarcity footprint (WF)

\section{Eradication of hunger}

The estimated environmental impacts as a result of zero hunger by 2030 are negligible. Calories consumption across the nations investigated would have to increase between $0.01 \%$ (Brazil) to $2.67 \%$ (India) when compared to the business-asusual scenario. Food deficits shrink between 2011 and 2030, especially in the case of Brazil. It highlights that there are hardly any trade-offs between environmental impacts and achieving the SDG2 goal of eradicating hunger. India and China see the largest benefits in prevented DALYs.

The assumed increased food production to eradicate hunger drives the environmental impacts. However, increased food production might be unnecessary to improve food security. By 2011, the dietary energy supply per capita (Fig. A2) was already higher than the average dietary energy requirement (Fig. A3) in all studied countries. Solving the paradox of hunger and obesity coexisting within a country (Steiner et al. 2019) by improving food access and redistributing food within its population may avoid any need for increased food production. Reducing food loss and waste offers another opportunity for enhanced food security without increased food production (Shafiee-Jood and Cai 2016). Besides, the environmental impacts of meeting zero-hunger targets are so low that the uptake of a vegetarian diet among some people in highincome parts of the populations could already offset these impacts (Marlow et al. 2009).

It remains uncertain if all countries will end hunger by 2030, as proposed in SDG2. While there was progress in previous decades, the related Millennium Development Goal to half hunger was not achieved and food insecurity has risen in recent years. More coherent policies and the right priorities are needed to reverse this trend (Cohen 2019), as well as solutions that are country-specific, adaptive and participatory (Blesh et al. 2019). In addition, climate change itself and related migration might pose new risks to food security (McMichael 2013). 
Fig. 6 Health improvements through the eradication of hunger in 2030 for a each undernourished person and $\mathbf{b}$ the total undernourished population. DALYs are disability-adjusted life years and HLEs are human life equivalents
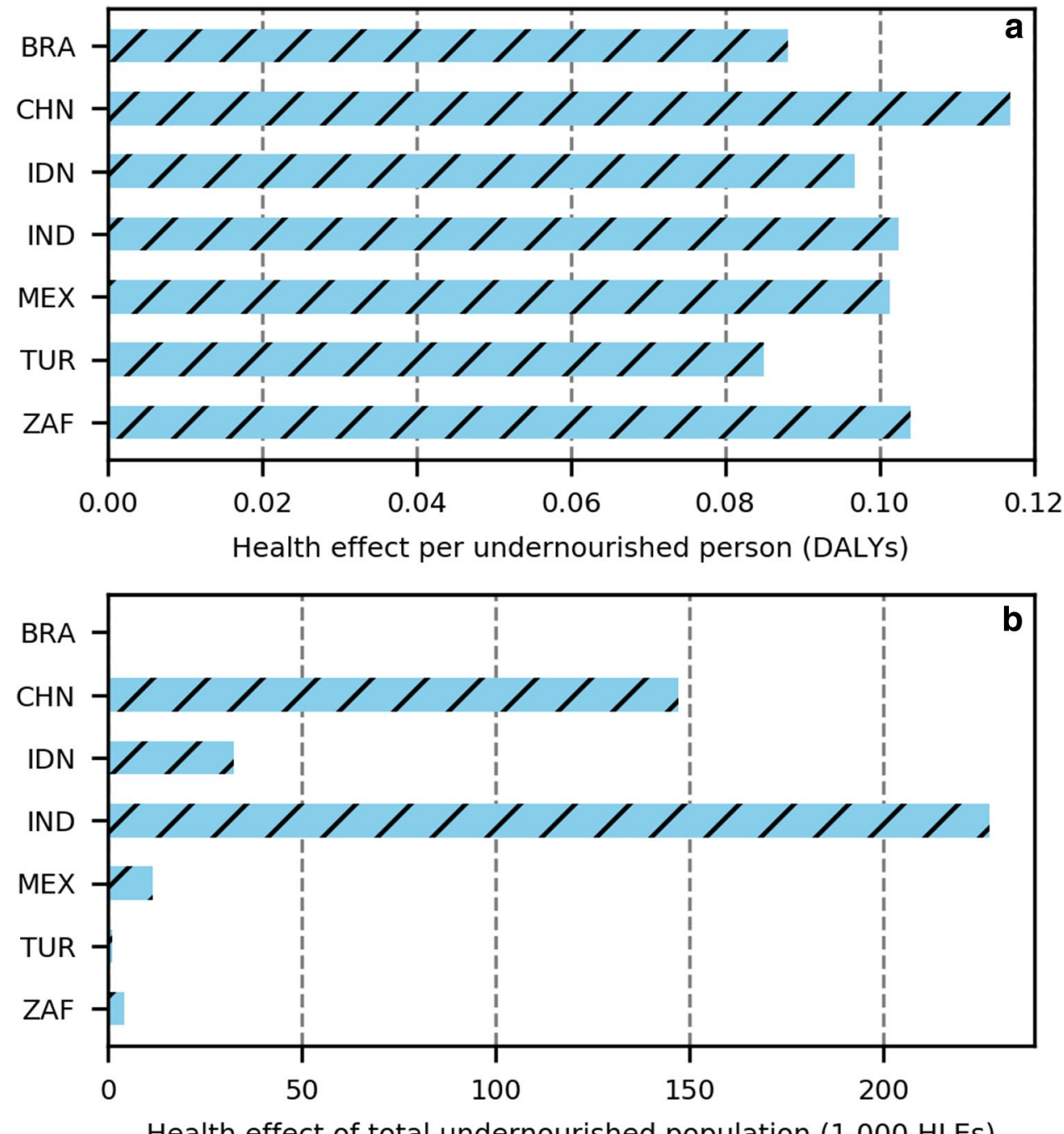

Health effect of total undernourished population (1,000 HLEs)

\section{Limitations}

Fundamentally, all results obtained in this study are based on projections which depend on many assumptions on how social, economic and environmental systems may change. In the following, we discuss some major sources of uncertainty but do not claim to be exhaustive.

There are numerous sources of uncertainty in EEIOA databases, such as sampling, measurement, aggregation and reporting errors. Harmonising data over several national or regional economies entails issues, such as industry concordance, monetary exchange rates and trade flow estimations. As the assessment is static, structural changes in the world economy between 2011 and 2030 remain unconsidered. Changes in trade could alter environmental impacts and technological advancements could allow for reductions. Presently, a hybrid (physical and monetary) table of EXIOBASE is being compiled, which is computationally more complex but could reduce uncertainty and simplify the translation of assessment results into policies (Merciai and Schmidt 2018).

The different product categorisations of EXIOBASE 3 and the AO can make harmonisation of the databases challenging. For example, high-fructose corn syrup is similar to sugar but has a range of uses as a sweetener and additive in beverages, dairy products, bread and various processed food products. In the US, uptake of high-fructose corn syrup consumption has coincided with an increase in noncommunicable diseases (Parker et al. 2010; Bray 2013). A higher product resolution in EEIOAs would allow for a more accurate analysis of its impacts. In addition, the AO does not consider the full range of food products: No equivalent to the EXIOBASE 3 categories 'Vegetables, fruit, nuts', 'Beverages', 'Food products nec' or 'Animal products nec' is included. Considering the demand growth for most categories until 2030, it is improbable that demand for these categories remains unchanged. This is significant, as, 'Food products nec', for example, represent the second-highest 
contributing food category to China's carbon footprint in 2011. 'Animal products nec' contain eggs, whose consumption is assumed to increase strongly, similar to vegetable consumption in India (Gandhi and Zhou 2014). The omission of these products may lead to an underreporting of dietary change and the associated changes in environmental impacts.

Our impact assessment only provides a simplified evaluation of global impacts, as characterisation factors are only an approximation. Characterisation factors for the carbon footprint, marine eutrophication and freshwater eutrophication per substance are applied globally without differentiating site-specific characteristics, as done for land stress and water scarcity. The characterisation factors for a specific impact category also represent a choice. For example for climate change, a different time horizon or a different metric, such as the global temperature change potential (Shine et al. 2005) instead of the global warming potential, could have been used.

The UN population prospects (2017) only provide data on limited age groups. Since there are formulas for total energy expenditure with higher accuracy (FAO et al. 2001), the calculation of the minimum dietary energy requirements could potentially be improved if population data is updated. The modelling of food security is merely done by raising the dietary energy supply of the undernourished population to the average dietary energy requirements. Thus, to what extent all micronutrients are covered by the different diets obtained in the business-as-usual scenario is not modelled. As an alternative to the lognormal distribution, the skewnormal distribution could also be used for calculating the prevalence of undernourishment (Asia and Pacific Commission on Agricultural Statistics 2014; Naiken 2014). The health impact indicator DALY and its application to assess the protein-energy malnutrition damage also represent a simplification. National differences and individual nutritional requirements remain unconsidered so that the results can only give a macro-level estimate.

\section{Opportunities for environmental impact mitigation}

The expected impact increases of emerging countries call for mitigation measures. It requires measures on both the supply and demand side of food systems (Scherer and Verburg 2017). This includes the optimisation of water irrigation, fertilizer use, fodder quality, energy inputs and manure treatment, among others (Jarvis et al. 1996; Usubiaga-Liaño et al. 2020; Yue et al. 2017). In China, the Ministry of Agriculture issued a policy to halt the increase in fertilizer use by 2020 (Yue et al. 2017). In general, the resource efficiencies in livestock farming have increased over time, as shown by Capper et al. (2009) using the example of dairy production in the US between 1944 and 2007. Moving towards diets following the nutritional advice of national institutions and containing fewer animal products would entail large decreases in GHG emissions, eutrophication and land use in Brazil, while GHG emissions would slightly decrease in China (Behrens et al. 2017). Our results likewise demonstrated a high impact intensity of animal products. Thus, the central question is how behavioural changes may develop, including a wider adoption of nationally recommended diets or a higher uptake of plant-based diets. Behaviour changes will necessarily be location-based. For instance, until now, there is no indication of declining beef consumption in Brazil (Ruby et al. 2016), while Buddhist communities might act as disseminators for vegetarianism in China (Kieschnick 2005).

Identifying and sharing key learning outcomes between countries regarding policies on sustainable food consumption is vital. The Global Alliance for Improved Nutrition (Gain 2014) argues that the trend of emerging countries adopting poor diets from the high-income world could be broken by leapfrogging the current food system and associated environmental impacts that derive from it. Our results suggest that India has the opportunity to establish food security while maintaining comparatively low p.c. meat intake, leading to a healthier and more environmentally viable nutritional pattern than foreseen by the nutrition transition. However, this does not apply to the water scarcity impacts of Indian diets which we find are the highest p.c. of all the nations investigated.

Importantly, with the increasing environmental challenge posed by the transition in emerging countries, it is incumbent upon high-income consumers to reduce their environmental impacts from diets. High-income nations are generally responsible for a higher proportion of environmental impacts from food and also import environmental damage from goods produced in lower-income nations (Sun et al. 2019). Overall, if lower-income nations can leapfrog the current food system and high-income nations can transition, we may see a global convergence to healthy and environmentally sustainable diets as called for in several publications including the EAT-Lancet commission (Willett et al. 2019). Because another global hotspot of the current nutrition transition is sub-Saharan Africa (Steyn and Mchiza 2014), further research should focus on investigating implications of dietary evolution in this region.

\section{Conclusions}

Here we investigated potential environmental impacts of the nutrition transition in emerging countries. We assessed impacts on climate change, marine and freshwater eutrophication, land stress and water scarcity. The highest impacts per country by 2030 are in Brazil for the land stress footprint (1.41 million $\mathrm{km}^{2}$ eq.), China for marine and freshwater 
eutrophication (1.15 Mt N eq. and 8.32 Mt P eq.) and India for the carbon and water scarcity footprints $\left(0.96 \mathrm{Gt} \mathrm{CO}_{2}\right.$ eq. and 661 billion $\mathrm{m}^{3}$ eq.). All impacts induced by the nutrition transition grow significantly. Total impact changes are highest for Indonesia (44-54\%, with the carbon footprint the highest among these), India (35-43\%, with the land stress footprint the highest among these) and Mexico (31-48\%, with marine eutrophication the highest among these). Parts of India and Indonesia are still consolidating the third pattern of the nutrition transition, indicating that the transition could still accelerate in these countries.

The need for efforts of eradicating hunger is highest in India and China, offering the possibility for great health improvements (about 375,000 human life equivalents of prevented DALYs combined). Eradicating hunger in 2030 while accounting for the projected nutrition transition leads to very small trade-offs with the environmental impacts studied here.

\section{References}

Aiking H (2011) Future protein supply. Trends Food Sci Technol 22:112-120. https://doi.org/10.1016/j.tifs.2010.04.005

Alae-Carew C, Bird FA, Choudhury S et al (2019) Future diets in India: a systematic review of food consumption projection studies. Glob Food Sec 23:182-190. https://doi.org/10.1016/J.GFS.2019.05.006

Aleksandrowicz L, Green R, Joy EJM et al (2019) Environmental impacts of dietary shifts in India: a modelling study using nationally-representative data. Environ Int 126:207-215. https://doi. org/10.1016/j.envint.2019.02.004

Asia and Pacific Commission on Agricultural Statistics (2014) Revision of the methodology for the estimation of the Prevalence of Undernourishment. Vientiane

Begum I, Rahman S, Alam MJ, et al (2011) Bangladesh poultry sector: growth, competitiveness and future potential. In: Livestock: Rearing, Farming Practices and Diseases. pp 81-104

Behrens P, Jong JCK, Bosker T et al (2017) Evaluating the environmental impacts of dietary recommendations. Proc Natl Acad Sci USA 114:13412-13417. https://doi.org/10.1073/pnas.1711889114

Blesh J, Hoey L, Jones AD et al (2019) Development pathways toward “zero hunger." World Dev 118:1-14. https://doi.org/10.1016/J. WORLDDEV.2019.02.004

Bouwman AF, Beusen AHW, Billen G (2009) Human alteration of the global nitrogen and phosphorus soil balances for the period 19702050. Glob Biogeochem Cycles. https://doi.org/10.1029/2009G B003576@10.1002/(ISSN)1525-2027.NUTRIENT1

Bray GA (2013) Energy and fructose from beverages sweetened with sugar or high-fructose corn syrup pose a health risk for some people. Adv Nutr 4:220-225. https://doi.org/10.3945/an.112.002816

Capper JL, Cady RA, Bauman DE (2009) The environmental impact of dairy production: 1944 compared with 2007. J Anim Sci 87:2160 2167. https://doi.org/10.2527/jas.2009-1781

Cohen MJ (2019) Let them eat promises: global policy incoherence, unmet pledges, and misplaced priorities undercut progress on SDG 2. Food Ethics 4:175-187. https://doi.org/10.1007/s4105 5-019-00048-2

Dhanda JS, Taylor DG, Murray PJ et al (2003) Goat meat production: present status and future possibilities. Asian-Aust J Anim Sci 16:1842-1852
FAO (2008) FAO methodology for the measurement of food deprivation-updating the minimum dietary energy requirements. FAO, Rome

FAO (2018) FAOSTAT. http://www.fao.org/faostat/en/\#home. Accessed 7 Dec 2018

FAO, WHO, UNU (2001) Human energy requirements-report of a Joint FAO/WHO/UNU Expert Consultation. FAO, Rome

Ferry M (2020) What's India's beef with meat? Hindu orthopraxis and food transition in India since the 1980s. Sociol Forum 35:511-534

Gain (2014) The 3 ways to fix the global food system. https://www. gainhealth.org/knowledge-centre/3-ways-fix-global-food-system/

Gallego B, Lenzen M (2006) A consistent input-output formulation of shared producer and consumer responsibility. Econ Syst Res 17:365-391. https://doi.org/10.1080/09535310500283492

Gandhi VP, Zhou Z (2014) Food demand and the food security challenge with rapid economic growth in the emerging economies of India and China. Food Res Int 63:108-124. https://doi. org/10.1016/J.FOODRES.2014.03.015

Gill M, Feliciano D, Macdiarmid J, Smith P (2015) The environmental impact of nutrition transition in three case study countries. Food Secur 7:493-504. https://doi.org/10.1007/s12571-015-0453-x

Gödecke T, Stein AJ, Qaim M (2018) The global burden of chronic and hidden hunger: trends and determinants. Glob Food Sec 17:21-29. https://doi.org/10.1016/J.GFS.2018.03.004

Godfray HCJ, Beddington JR, Crute IR et al (2010) Food security: the challenge of feeding 9 billion people. Science (80-) 327:812-818. https://doi.org/10.1126/science.1185383

Godfray HCJ, Aveyard P, Garnett T et al (2018) Meat consumption, health, and the environment. Science (80-). https://doi. org/10.1126/SCIENCE.AAM5324

Gustavsson J, Cederberg C, Sonesson U (2011) Global food losses and food waste: extent, causes and prevention. Food and Agriculture Organization of the United Nations (FAO), Swedish Institute for Food and Biotechnology (SIK)

Guyomard H, Manceron S, Peyraud J-L (2013) Trade in feed grains, animals, and animal products: current trends, future prospects, and main issues. Anim Front 3:14-18. https://doi.org/10.2527/ af.2013-0003

Harper LA, Denmead OT, Freney JR, Byers FM (1999) Direct measurements of methane emissions from grazing and feedlot cattle. J Anim Sci 77:1392. https://doi.org/10.2527/1999.7761392x

Harris F, Moss C, Joy EJM et al (2020) The water footprint of diets: a global systematic review and meta-analysis. Adv Nutr 11:375386. https://doi.org/10.1093/advances/nmz091

Hocquette J-F (2016) Is in vitro meat the solution for the future? Meat Sci 120:167-176. https://doi.org/10.1016/J.MEATS CI.2016.04.036

INDDEX Project (2018) Data4Diets: building blocks for diet-related food security analysis. https://inddex.nutrition.tufts.edu/data4diets

Jarvis SC, Wilkins RJ, Pain BF (1996) Opportunities for reducing the environmental impact of dairy farming managements: a systems approach. Grass Forage Sci 51:21-31. https://doi. org/10.1111/j.1365-2494.1996.tb02034.x

Jolliet O, Antón A, Boulay A-M et al (2018) Global guidance on environmental life cycle impact assessment indicators: impacts of climate change, fine particulate matter formation, water consumption and land use. Int J Life Cycle Assess 23:2189-2207. https://doi. org/10.1007/s11367-018-1443-y

Kassebaum NJ, Arora M, Barber RM et al (2016) Global, regional, and national disability-adjusted life-years (DALYs) for 315 diseases and injuries and healthy life expectancy (HALE), 1990-2015: a systematic analysis for the Global Burden of Disease Study 2015. Lancet 388:1603-1658. https://doi.org/10.1016/S0140 $-6736(16) 31460-X$

Kieschnick J (2005) Buddhist vegetarianism in China. Of tripod and palate. Palgrave Macmillan US, New York, pp 186-212 
Lenzen M, Murray J, Sack F, Wiedmann T (2007) Shared producer and consumer responsibility-theory and practice. Ecol Econ 61:27-42. https://doi.org/10.1016/J.ECOLECON.2006.05.018

Machovina B, Feeley KJ, Ripple WJ (2015) Biodiversity conservation: the key is reducing meat consumption. Sci Total Environ 536:419-431. https://doi.org/10.1016/j.scitotenv.2015.07.022

Mäenpää I, Siikavirta H (2007) Greenhouse gases embodied in the international trade and final consumption of Finland: an input-output analysis. Energy Policy 35:128-143. https://doi. org/10.1016/J.ENPOL.2005.10.006

Marlow HJ, Hayes WK, Soret S et al (2009) Diet and the environment: does what you eat matter? Am J Clin Nutr 89:1699S-1703S. https://doi.org/10.3945/ajen.2009.26736Z

McMichael C (2013) Climate change and migration: food insecurity as a driver and outcome of climate change-related migration. In: Environmental deterioration and human health. pp 291-313

Merciai S, Schmidt J (2018) Methodology for the construction of global multi-regional hybrid supply and use tables for the EXIOBASE v3 database. J Ind Ecol 22:516-531. https://doi. org/10.1111/jiec.12713

Milford AB, Le Mouël C, Bodirsky BL, Rolinski S (2019) Drivers of meat consumption. Appetite 141:104313. https://doi. org/10.1016/J.APPET.2019.06.005

Moltedo A, Troubat N, Lokshin M, Sajaia Z (2014) Analyzing food security using household survey data

Munksgaard J, Pedersen KA (2001) $\mathrm{CO}_{2}$ accounts for open economies: producer or consumer responsibility? Energy Policy 29:327-334. https://doi.org/10.1016/S0301-4215(00)00120-8

Myhre G, Shindell D, Bréon F-M, et al (2013) Anthropogenic and natural radiative forcing

Naiken L (2003) Keynote paper: FAO methodology for estimating the prevalence of undernourishment. Rome

Naiken L (2014) Methodological isses in the estimation of the prevalence of undernourishment based on dietary energy consumption data: a review and clarification. Rome

O'Riordan T, Stoll-Kleemann S (2015) The challenges of changing dietary behavior toward more sustainable consumption. Environ Sci Policy Sustain Dev 57:4-13

OECD (2018) OECD.Stat. https://stats.oecd.org/

OECD, FAO (2015) Aglink-cosimo model documentation a partial equilibrium model of world agricultural markets

OECD, FAO (2018) OECD-FAO agricultural outlook 2018-2027

Parker K, Salas M, Nwosu VC (2010) High fructose corn syrup: production, uses and public health concerns. Biotechnol Mol Biol Rev 5:71-78

Pfister S, Bayer P (2014) Monthly water stress: spatially and temporally explicit consumptive water footprint of global crop production. J Clean Prod 73:52-62. https://doi.org/10.1016/J.JCLEP RO.2013.11.031

Pfister S, Bayer P, Koehler A et al (2011) Environmental impacts of water use in global crop production: hotspots and trade-offs with land use. Environ Sci Technol 45:5761-5768. https://doi. org/10.1021/es1041755

Pfister S, Boulay A-M, Berger M et al (2017) Understanding the LCA and ISO water footprint: a response to hoekstra (2016) "a critique on the water-scarcity weighted water footprint in LCA." Ecol Indic 72:352-359

Popkin BM (1993) Nutritional patterns and transitions. Popul Dev Rev 19:138-157

Ramankutty N, Mehrabi Z, Waha K et al (2018) Trends in global agricultural land use: implications for environmental health and food security. Annu Rev Plant Biol. https://doi.org/10.1146/ annurev-arplant-042817

Roser M, Ritchie H (2017) Meat production \& consumption-our world in data. In: Our world data
Roser M, Ritchie H (2018a) Hunger and undernourishment-our world in data. In: Our world data. https://ourworldindata.org/ hunger-and-undernourishment. Accessed 26 Jan 2020

Roser M, Ritchie H (2018b) Food per person-our world in data. In: Our world data. https://ourworldindata.org/food-per-perso n. Accessed 6 Dec 2018

Ruby MB, Alvarenga MS, Rozin P et al (2016) Attitudes toward beef and vegetarians in Argentina, Brazil, France, and the USA. Appetite 96:546-554. https://doi.org/10.1016/J.APPET 2015.10.018

Scherer L, Pfister S (2016) Dealing with uncertainty in water scarcity footprints. Environ Res Lett. https://doi.org/10.1088/17489326/11/5/054008

Scherer L, Verburg PH (2017) Mapping and linking supply- and demand-side measures in climate-smart agriculture. A review. Agron Sustain Dev 37:2

Scherer L, Behrens P, de Koning A et al (2018) Trade-offs between social and environmental sustainable development goals. Environ Sci Policy 90:65-72. https://doi.org/10.1016/J.ENVSC I.2018.10.002

Scherer L, Behrens P, Tukker A (2019) Opportunity for a dietary win-win-win in nutrition, environment, and animal welfare. One Earth, Culver

Shafiee-Jood M, Cai X (2016) Reducing food loss and waste to enhance food security and environmental sustainability. Environ Sci Technol 50:8432-8443

Shine KP, Fuglestvedt JS, Hailemariam K, Stuber N (2005) Alternatives to the global warming potential for comparing climate impacts of emissions of greenhouse gases. Clim Change 68:281-302. https://doi.org/10.1007/s 10584-005-1146-9

Simoes A, Hidalgo C (2011) The economic complexity observatory: an analytical tool for understanding the dynamics of economic development. In: Work. Twenty-Fifth AAAI Conf. Artif. Intell. https://oec.world/en/

Smil V (2002) Worldwide transformation of diets, burdens of meat production and opportunities for novel food proteins. Enzyme Microb Technol 30:305-311

Smith J, Sones K, Grace D et al (2013) Beyond milk, meat, and eggs: role of livestock in food and nutrition security. Anim Front 3:613. https://doi.org/10.2527/af.2013-0002

Stadler K, Wood R, Bulavskaya T et al (2018) EXIOBASE 3: developing a time series of detailed environmentally extended multiregional input-output tables. J Ind Ecol 22:502-515. https://doi. org/10.1111/jiec. 12715

Steiner G, Geissler B, Schernhammer ES (2019) Malnutrition, hunger and obesity as symptoms of non-sustainable food systems and malnutrition. Appl Sci 9:1062

Steyn NP, Mchiza ZJ (2014) Obesity and the nutrition transition in Sub-Saharan Africa. Ann N Y Acad Sci 1311:88-101. https:// doi.org/10.1111/nyas. 12433

Subak S (1999) Global environmental costs of beef production. Ecol Econ 30:79-91. https://doi.org/10.1016/S0921-8009(98)00100 $-1$

Sun Z, Scherer L, Tukker A, Behrens P (2019) Linking global crop and livestock consumption to local production hotspots. Glob Food Sec. https://doi.org/10.1016/j.gfs.2019.09.008

The World Bank (2019) Life expectancy at birth, total (years) I Data. https://data.worldbank.org/indicator/sp.dyn.le00.in

UN (2017) World population prospects-the 2017 revision. https:// population.un.org/wpp/. Accessed 6 Dec 2018

UN (2018) Sustainable development goals-Goal 2: Zero Hunger. https ://www.un.org/sustainabledevelopment/hunger/

USDA (2019) USDA food composition databases. https://ndb.nal.usda. gov/ndb/. Accessed 17 May 2019

Usubiaga A, Butnar I, Schepelmann P (2017) Wasting food, wasting resources. J Ind Ecol. https://doi.org/10.1111/jiec.12695 
Usubiaga-Liaño A, Behrens P, Daioglou V (2020) Energy use in the global food system. J Ind Ecol jiec. https://doi.org/10.1111/ jiec. 12982

Willett W, Rockström J, Loken B et al (2019) Food in the anthropocene: the EAT-lancet commission on healthy diets from sustainable food systems executive summary. Lancet. https://doi. org/10.1016/S0140-6736(18)31788-4

Woodard DL, Davis SJ, Randerson JT (2019) Economic carbon cycle feedbacks may offset additional warming from natural feedbacks. Proc Natl Acad Sci U S A 116:759-764. https://doi.org/10.1073/ pnas. 1805187115

Xue X, Landis AE (2010) Eutrophication potential of food consumption patterns. Environ Sci Technol 44:6450-6456. https://doi. org/10.1021/es9034478
Yue Q, Xu X, Hillier J et al (2017) Mitigating greenhouse gas emissions in agriculture: from farm production to food consumption. J Clean Prod 149:1011-1019. https://doi.org/10.1016/J.JCLEP RO.2017.02.172

Publisher's Note Springer Nature remains neutral with regard to jurisdictional claims in published maps and institutional affiliations. 